\title{
Secretion of middle ear in infants - occurrence, recurrence and related factors
}

\author{
Sandra de O. Saes, ${ }^{1}$ Tamara B. L. Goldberg, ${ }^{2}$ Jair C. Montovani ${ }^{3}$
}

\begin{abstract}
Objective: The present study aimed at evaluating the occurrence and recurrence of middle ear effusion and possible associated factors in the first two years of life of 190 newborns and infants, participants in the interdisciplinary prevention, detection, and intervention program at the Clínica de Educação para Saúde of Universidade do Sagrado Coração.
\end{abstract}

Methods: Newborns and infants were monthly submitted to anamneses, otoscopy, behavioral hearing assessment using sound instruments and pure tones (pediatric audiometry) and tympanometry.

Results: The results revealed that $68.4 \%$ of infants presented one or more episodes of middle ear effusion during their two first years, with more recurrence among males. Peak occurrence was between four and 12 months of age and, the earlier the first episode, the higher the probability of recurrence. Greatest incidence was during May and August. It was found that, of the variables investigated, the period of exclusive breastfeeding actuated as a protector factor. With respect of risk factors, it was observed that passive smoking, gastro-esophageal reflux and respiratory allergy were related with the recurrences of effusion.

Conclusion: Findings revealed the importance of periodic auditory follow-up for infants during their first two years of life, considered to be the critical period of auditory system maturation, during which sensory deprivation can be responsible for damage to the development of speech, language and other auditory abilities.

J Pediatr (Rio J). 2005;81(2):133-8: Otoscopy, otitis media, acoustic impedance tests.

\section{Introduction}

Otitis media with secretion (OME) is defined as the presence of fluid in the middle ear with no signs or symptoms of acute infection. It is accompanied by episodic and variable conductive auditory losses, which can vary in severity from mild to moderate, not exceeding $50 \mathrm{~dB}$. It

1. PhD. Professor, Universidade do Sagrado Coração, Bauru, SP, Brazil.

2. PhD. Assistant professor, Department of Pediatrics, Faculdade de Medicina de Botucatu, Universidade Estadual Paulista (UNESP), Botucatu, SP, Brazil.

3. Full professor, Department of Ophtalmology, Otorhinolaryngology and Neck and Head Surgery, Faculdade de Medicina de Botucatu, UNESP, Botucatu, SP, Brazil.

* This paper is part of the PhD dissertation of the first author.

Manuscript received Mar 26 2004, accepted for publication Dec 222004

Suggested citation: Saes SO, Goldberg TB, Montovani JC. Secretion of middle ear in infants - occurrence, recurrence and related factors. J Pediatr (Rio J). 2005;81:133-8. generally has onset during the first years of life and, according to some authors, ${ }^{1-3}$ can be blamed for several different types of development deficiencies seen at later stages of childhood.

Our clinical practice demonstrates that the sensory deprivation resulting from $O M E$, aggravated by the number and duration of episodes, can affect speech perception and make understanding more difficult, particularly in noisy surroundings, and can even prejudice the children's language development. Therefore, the prevention, detection and monitoring of otological diseases, particularly those that affect children during their first years of life, is of fundamental importance. All available resources should be employed to detect auditory deficiencies.

Based on this assumption, the present study took as its objective the detection of middle ear secretion during the 2 first years of life, by means of otoscopy, behavioral auditory assessment, and tympanometry in addition to investigating their correlation with risk factors. 


\section{Methods}

Five hundred and thirty-four infants between 0 and 2 years of age were selected. All had been born between August 1997 and August 1999, meaning that in September 2001, when data was analyzed all were at least 2 years old. The infants were participants on the follow-up study called the Multidisciplinary Prevention Detection and Intervention Program, developed by the Health Education Clinic at the Universidade do Sagrado Coração de Bauru (São Paulo). Initially the mothers were invited to participate in the program. Next the children were made appointments at the Maternity Unit of the Hospital Beneficência Portuguesa in the town of Bauru (São Paulo), irrespective of their presenting any developmental risk factors. One hundred and ninety of the 534 children enrolled on the program were included in the present study with the other 344 presenting one or more exclusion criterion. The criteria were: gestational age of less than 37 weeks; diagnosis of progressive or non-progressive chronic childhood encephalopathy, neuropsychomotor retardation; progressive or non-progressive sensorineural hearing loss; malformations and acute and chronic diseases of the middle ear; history of syphilis; birth weight below $2,500 \mathrm{~g}$; use of ototoxic pharmaceuticals and other risk factors for auditory abnormalities according to the Joint Committee on Infant Hearing (2000) ${ }^{4}$ and, finally, two consecutive missed appointments or a total of five over the 2-year period.

Because this was a longitudinal study, the sample of 190 infants was considered sufficient for the statistical analysis performed.

All of the infants' parents or guardians were informed of the program objectives and were told of the ethical features that guaranteed total confidentiality by preserving anonymity, in accordance with Resolution $196 / 96^{5}$ on Ethics in Research with Human Beings. If in agreement the responsible adults signed a consent form termed Authorization of Diagnosis and Treatment.

Subjects underwent monthly otoscopic evaluations performed by an otorhinolaryngologist. All of the infants were followed-up for 2 years, but as they were born over a period of time, the observation period lasted for 4 years. They also underwent auditory behavior analysis by a speech therapist using: musical instruments (rattle, reco-reco [springs strung on a sounding board], bell, black-black [similar to castanets, but with handles] and agogô [twin, cone-shaped bells]) held along the lateral plane and, after 6 months, also in the vertical plane, mother's voice unamplified and pediatric audiometer (from the ninth month onwards) at 500, 1,000, 2,000 and 4,000 Hz frequencies and intensities from 20 to $80 \mathrm{~dB}$ (at $20 \mathrm{~dB}$ increments). Responses were assessed in accordance with the children's ages, global development, state of wakefulness during the assessment and the acoustic characteristics of the sound stimulus used. ${ }^{6}$ Tests were performed with the infant in a state of conscience defined by Brazelton 7 as level 5 , i.e. eyes open, considerable motor activity, with brisk movements of the extremities and even some spontaneous jerks, reacting to external stimulus with increased jerking or motor activity. Assessments were performed by two observers. In the event that results were discordant, a third observer was asked to reassess the subject. These evaluations were made with the objective of determining the development of the infants' ability to locate sounds, although this is not the subject of this article. We would further point out that, in this analysis, the behavioral assessment was performed as an accessory technique for judging auditory acuity, serving merely as support and supplement to the tympanometry findings. The other procedure performed was tympanometry, considered an important resource, since it provides information on the mobility status of the tympano-ossicular system and on the global integrity of the auditory tubes. ${ }^{8}$ It has a high sensitivity for detection of middle ear secretion characterized by the presence of type $B$ and $C_{2}$ tympanometric curves. ${ }^{9,10}$ Tympanometric results were classified as per Jerger ${ }^{11}$ as modified by Nikolajsen, 12 i.e. middle ear secretion was diagnosed if types $\mathrm{B}$ and $\mathrm{C}_{2}$ tympanometric curves were found in addition to otoscopic findings.

The auditory behavior analysis with instruments and the tympanometry were performed in a room without soundproofing, but the noise level was below $40 \mathrm{~dB}$. Tympanometry was performed using an Interacoustics AZ7R impedance audiometer. Pediatric audiometry was performed in an acoustic cabin, and the equipment employed was an Interacoustics PA2 pediatric audiometer. The equipment was calibrated according to ANSI 3. ISO 389 standards.

Presence of middle ear secretion was confirmed when both otoscopy and tympanometry findings agreed. In cases of disagreement, the abnormality was considered independently of the diagnostic procedure. In order to guarantee greater reliability between otoscopy and tympanometry, the results were subjected to a statistical analysis, with an agreement index above $95 \%$.

In confirmed cases of middle ear secretion infants were referred for medical evaluation and, after treatment, returned in 15 days. If secretion persisted then this was considered to be the same single episode, being defined as persistent middle ear secretion for a prolonged period. Fresh episodes were only recorded after intervening evaluations had once more returned normal results.

The results were analyzed statistically by means of the chi-square test and contingency coefficient (C) for association measurement. The variables studied were: sex, age, socioeconomic level, season, length of natural breastfeeding, presence of gastroesophageal reflux (GER), allergies and history of passive smoking. For all statistics calculated significance was set at $p<0.05 .13$

\section{Results}

Of the 190 infants followed, 98 were male and 92 were female. Distribution of episodes of middle ear secretion occurrence and recurrence by sex is shown in Table 1. By means of statistical analysis a greater frequency of four or more episodes was verified among male infants. 
Table 1 - Distribution of episodes of middle ear secretion occurrence and recurrence by sex of infants and newborns

\begin{tabular}{lcccc}
\hline Sex & \multicolumn{4}{c}{$\mathbf{n}$ of episodes } \\
\cline { 2 - 5 } & $\mathbf{0}$ & $\mathbf{1 - 3}$ & $\mathbf{4}$ or + & Total \\
\hline Male & $33(30.9)$ & $41(49.0)$ & $24(18.6)$ & 98 \\
Female & $27(29.1)$ & $54(46.0)$ & $11(16.4)$ & 92 \\
Total & 60 & 95 & 35 & 190 \\
\hline
\end{tabular}

$\chi^{2}=7.783 ; p=0.05 ; C=0.180$.

( ) value expected according to the statistical analysis.

Figure 1 demonstrates the occurrence and recurrence of secretion episodes according to the age in months of the infants.

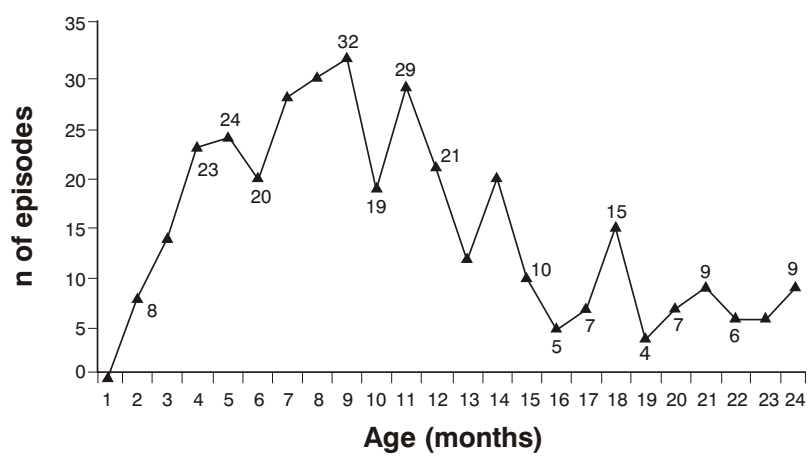

Figure 1 - Occurrence and recurrence of secretion episodes type $B$ and $C_{2}$ according to age in months of newborns and infants
Among the factors related to the appearance of middle ear secretion, it was observed that the age at which the first episode occurred was directly associated with its recurrence. The statistical analysis revealed that infants who had had their first episode after 7 months, presented a lower rate of recurrence. The inverse was observed in cases in which the first episode occurred before the sixth month, i.e. this group exhibited a greater number of recurrences (Table 2 ).

With respect of the relation between predominant maternal breastfeeding and occurrence and recurrence of middle ear secretion, the statistical analysis showed that the greater the period of predominant natural breastfeeding, with this being more than 10 months, the lower the incidence of the first episode appearing during the first six months and of recurrence of four or more episodes. The inverse relation was observed for the group of infants whose period of predominant natural breastfeeding had been less than 6 months, i.e. this subset exhibited a greater incidence of recurrence and also of the first episode taking place during the first six months of life (Table 3 ).

Of the other factors that were studied, the presence of GER, and of allergic respiratory manifestations and respiratory manifestations associated with other types of allergy, exhibited a positive association with occurrence and recurrence of middle ear secretion, as can be observed in Figures 2 and 3, respectively. With respect of passive smoking a tendency was observed towards a positive association with the recurrence of episodes of middle ear secretion (Figure 4).

With respect of seasonality, a greater rate of occurrence and recurrence was observed during the colder months of the year, during autumn and winter (57.6\%).

No significant relationships were found for the variables referring to socio-economic level and color.

Table 2 - Distribution of middle ear secretion occurrence and recurrence episodes by infants and newborns age at the first episode

\begin{tabular}{lccccc}
\hline First episode & \multicolumn{5}{c}{$\mathbf{n}$ of episodes } \\
\cline { 2 - 6 } & $\mathbf{1}$ & $\mathbf{2}$ & $\mathbf{3}$ & $\mathbf{4}$ or + & Total \\
\hline Up to 3 months & $5(6.3)$ & $4(6.3)$ & $9(3.5)$ & $4(5.9)$ & 22 \\
4 to 6 months & $7(14.8)$ & $16(14.8)$ & $4(8.4)$ & $25(14.0)$ & 52 \\
7 to 9 months & $11(9.1)$ & $11(9.1)$ & $6(5.2)$ & $4(8.6)$ & 32 \\
More than 9 months & $14(6.8)$ & $6(6.8)$ & $2(3.9)$ & $2(6.5)$ & 24 \\
Total & 37 & 37 & 21 & 35 & 130 \\
\hline
\end{tabular}

$\chi^{2}=40.220 ; \mathrm{p}<0.01 ; \mathrm{C}=0.486$

( ) value expected according to the statistical analysis. 
Table 3 - Distribution of middle ear secretion episodes according to predominant natural breastfeeding period of infants and newborns

\begin{tabular}{lcccc}
\hline Predominant & \multicolumn{4}{c}{$\mathbf{n}$ of episodes } \\
\cline { 2 - 5 } natural breastfeeding period & $\mathbf{0}$ & $\mathbf{1 ~ - ~} \mathbf{4}$ & $\mathbf{4}$ or + & Total \\
\hline Up to 3 months & $24(22.6)$ & $39(36.7)$ & $13(13.7)$ & 76 \\
4 to 6 months & $11(16.1)$ & $26(26.1)$ & $15(9.7)$ & 52 \\
7 to 9 months & $8(9.3)$ & $17(15.1)$ & $5(5.6)$ & 30 \\
More than 10 months & $17(9.9)$ & $13(16.1)$ & $2(6.0)$ & 32 \\
Total & 60 & 95 & 35 & 190 \\
\hline
\end{tabular}

$\chi^{2}=13.450 ; p<0.05 ; C=0.259$.

( ) value expected according to the statistical analysis.

\section{Discussion}

The incidence of middle ear secretion during the 2 first years of life has been described by a number of different authors, ${ }^{14}$ and their findings are comparable to those of the present study $(68.4 \%)$. This occurrence is a warning that health and education professionals need to be alert for manifestations that could suggest compromised auditory tubes and should implement programs aimed at prevention, diagnosis and treatment, in particular because of the fact that the first years of life are considered a critical period for development.

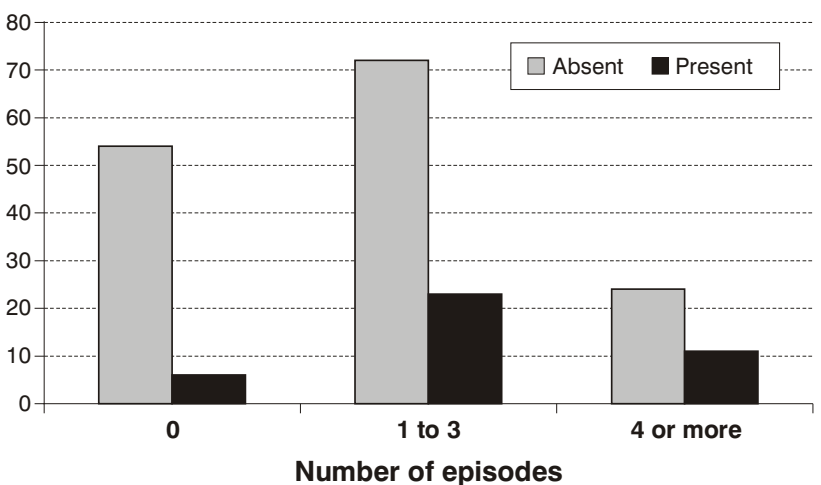

$\chi^{2}=10.075 ; p<0.02 ; C=0.224$

Figure 2 - Infants and newborns distributed according to the first occurrence and recurrence of middle ear secretion

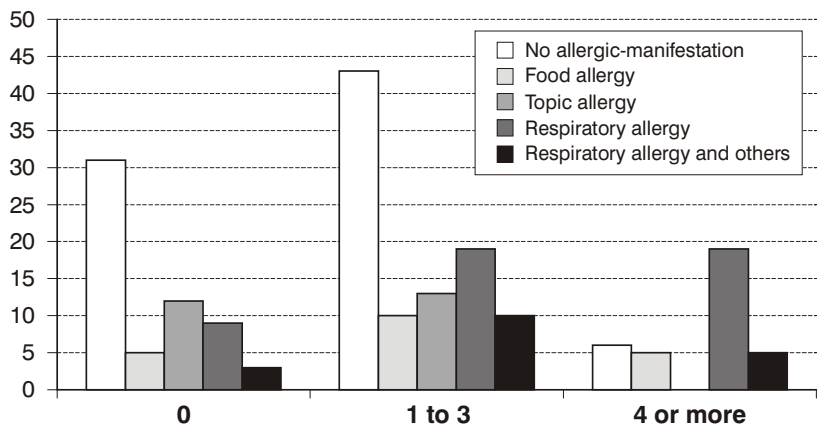

Number of epsiodes

$\chi^{2}=31.725 ; \mathrm{p}<0.001 ; \mathrm{C}=0.378$

Figure 3 - Infants and newborns distributed according to absence, recurrence and occurrence of middle ear secretion, and predominant natural breastfeeding period

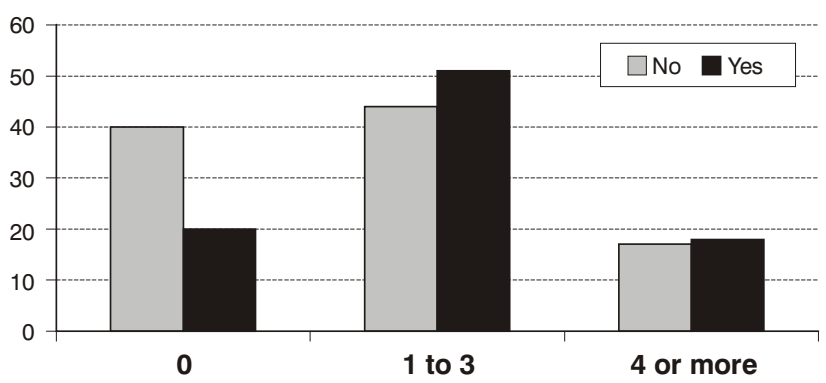

$\chi^{2}=6.485 ; 0.05<p<0.10 ; C=0.182$

Figure 4 - Infants and newborns distributed according to absence, occurrence and recurrence of middle ear secretion, and the presence of gastroesophageal reflux 
The statistical analysis revealed a significant difference between the sexes, with greater occurrence - four or more episodes - for males. The prevalence of otitis media towards the male sex has been described in studies by Birch \& Elbrond. ${ }^{15}$ For Spila et al., ${ }^{16}$ this is a result of the fact that boys exhibit less efficient mucociliary transport and tube function than do girls. Nevertheless, studies by van Cauwenberge ${ }^{17}$ and Zielhuis et al. ${ }^{18}$ did not find any greater occurrence of middle ear secretion among boys.

Figure 1 illustrates greater rates of occurrence of secretion between the fourth and 12th months of life. It is, therefore, during the first year that the period of greatest incidence of middle ear secretion occurs. Comparable data are described in a number of different published studies. ${ }^{19,20}$

It was verified that early appearance of the first episode of middle ear secretion, i.e. those diagnosed during the first 6 months of life, was directly related with the recurrence of four or more episodes, with the same having been observed in both Brazilian and international studies. ${ }^{14,19}$

The association between middle ear secretion and the length of predominant natural breastfeeding was studied and it was found that children who were breastfed for up to 6 months had a greater rate of recurrence of four or more episodes, with the reverse being verified for infants breastfed past 10 months, i.e. a lower rate of occurrence and recurrence. A number of different authors have shown a lower rate of otitis media among infants who received maternal breastfeeding for prolonged periods. 21,22

The current study returned results that reinforce those to be found in the literature, emphasizing the importance of maternal breastfeeding and the need for greater involvement by health professionals, who have to cooperate greatly so that breastfeeding is initiated and continued, favoring and offering better quality of life to children.

Other aspects that were studies, such as the presence of GER and allergic manifestations, showed positive associations with the recurrence of middle ear secretion. Passive smoking exhibited a tendency towards a positive association.

Despite the existence of a great deal of material and information in the scientific literature involving otorhinolaryngological manifestations and gastroesophageal reflux disease (GERD), a small amount of this material reports on middle ear involvement, including OME together with GER. White et al., ${ }^{23}$ using an animal model to test the influence of GER on auditory tube dysfunction, exposing the nasopharynx to pepsin and hydrochloric acid at similar concentrations to those in gastric juices, observed auditory tube and mucociliary clearance dysfunction. Poelmans et al. ${ }^{24}$ studying patients with middle ear secretion and GER, found remission of the otitis when anti-GER treatment was instituted.

We emphasize that in our study the diagnoses of GER were made according to the pediatric diagnoses provided and diagnostic procedures, investigations and treatments carried out were not examined.
Although GERD is much discussed and attention is paid to the complications it causes, in cases in which the diagnosis is confirmed or suspicious symptomology exists, special attention must be paid to the auditory aspects, bearing in mind the risk of middle ear secretion and the insidious characteristics of this disease, particularly in infants.

A number of different studies have researched the relationship between OME and allergies, with conflicting results. Some authors did not observe any interaction, 22,25 while others found a positive association, with atopic phenomena being considered as risk factors for otitis. ${ }^{26-28}$

Overall, the results of such studies and of this one warn of the need for continuous research into the subject and allergic control of patients suffering from middle ear secretion, which could reduce or extinguish these occurrences and their complications, promoting better quality of life for patients.

The association of passive smoking with middle ear secretion has been described by a number of different authors. ${ }^{19,29,30}$ Analyzing the findings of this study and the evidence described in the literature that was consulted, passive smoking should be widely combated by health and education professionals and governments which would offer benefits for the health of smokers and those who live with them.

The increased occurrence and recurrence of middle ear secretion during the colder months of the year is related to the increase in infectious and inflammatory processes in the airways and the resulting upper airway and auditory tube obstructions and otitis observed during this period. Comparable data were found in studies by Hubig \& Costa Filho, ${ }^{14}$ Pereira $\&$ Ramos $^{19}$ and Midgley et al. ${ }^{31}$

The socioeconomic analysis of the sample did not take account of whether patients lived with other children, or if they had spent time in nurseries or day-care although these are risk factors for middle ear secretion that have been discussed in the literature.

In the present study no was statistically significant differences were observed between different social classes, which might be attributable to the fact that only the economic characteristics and the systematic guidance of families were considered, which favors more appropriate and helpful behavior, preventing the occurrence of health problems. According to Hubig \& Costa Filho ${ }^{14}$ and Roberts et al. ${ }^{20}$ socio-economic level should not be looked at in isolation, but within a context that involves general environmental, nutritional and health conditions. With respect of color, there is a prevalence of otitis media for the white race, being less frequent in the black race, ${ }^{32}$ however such a prevalence was not confirmed in our study.

The present study found an elevated incidence of episodes of middle ear secretion in infants, warning of the need for greater attention on the part of parents, educators and health professionals to be paid to otological problems in early childhood, which can result in auditory losses that, although they do not make language acquisition unviable, can compromise the development of linguistic abilities, 
reflecting on performance at school. Knowing that a child has a hearing problem is important, but it is not everything. It is also relevant to explain to parents and educators the conduct that should be adopted in order to participate more actively in prevention of the problem, helping not just with auditory and language development, but also promoting better quality of life for their children.

\section{References}

1. Fria TJ, Cantekin EI, Eichler J. Hearing acuity of children with otitis media with effusion. Arch Otolaryngol Head Neck Surg. $1985 ; 111: 10-6$.

2. Santos TMM. Otite média: implicações para o desenvolvimento da linguagem. In: Schochat E,org. Processamento auditivo. Série Atualidades em Fonoaudiologia. São Paulo: Lovise; 1996. p. 107-24.

3. Sininger YS, Doyle KJ, Moore JK. As vantagens da identificação precoce da perda auditiva em crianças. Clin Pediatr Am Norte 1999;46:1-13.

4. American Speech-Language-Hearing Association [homepage on the Internet]. Rockville, Maryland: (c)1997-2005 American Speech-Language-Hearing Association [updated 2003, Aug 30; cited 2005 Mar 4]. Joint Committee on Infant Hearing. Year 2000 position statement: principles and guidelines for early hearing detection and intervention programs. [about 27 screens]. Disponível em: http://www.asha.org/about/legislationadvocacy/federal/ehdi/y2kpstn_stmnt.htm

5. Brasil. Conselho nacional de saúde (1996). Resolução 196/69. In: ComissãoNacional de Etica em Pesquisa (2000).Normas para pesquisa em seresHumanos. Brasília: Ministério da Saúde. p. 22-46.

6. Costa SA. Interpretando uma avaliação audiológica infantil. In: Gama MR, org. Resolvendo casos em audiologia. São Paulo: Plexus; 2001. p. 71-97.

7. Brazelton TB. The manual. In: Neonatal behavioral assessment scale. 2nd ed. Philadelphia: Spatics International Medical Publications; 1984. p. 17-77.

8. Carvallo RMM. Medidas da imitância acústica em crianças de 0 a 8 meses de idade [dissertação]. São Paulo: Escola Paulista de Medicina; 1992.

9. Franche GLS, Tabajara LMV, Arrarte JLF, Saffer M. Otoscopia e timpanometria no diagnóstico de otite média secretora. J Pediatr (Rio J). 1998;74:365-7.

10. Johansen EC, Lildholdt T, Damsbo N, Eriksen EW. Tympanomety for diagnosis and treatment of otitis media in general pratice. Fam Pract. 2000;17:317-22.

11. Jerger J. Clinical experience with impedance audiometry. Arch Otolaryngol. 1970;92:311-24.

12. Nikolajsen MF. Tympanometry and secretory otitis media. Acta Otolaryngol Suppl (Stockl).1983;96:1-73.

13. Curi PR. Metodologia e análise da pesquisa em ciências biológicas. $2^{a}$ ed. Botucatu: Tipomic; 1998.

14. Hubig DOC, Costa Filho OA. Otite média: considerações em relação à população de creche. In: Lichtig I, Carvallo RMM. Audição: abordagens atuais. Carapicuíba: Pró-fono; 1997. p. 89-117.

15. Birch L, Elbrond O. A prospective epidemiological study of secretory otitis media in young children related to the indoor environment. ORL J Otorhinolaryngol Relat Spec. 1987;49:253-8.
16. Spila M, Pukander J, Karma P. Incidence of acute otitis media up to the age of $1 \frac{1 / 2}{2}$ years in urban infants. Acta Otolaryngol. 1987; 104:138-45.

17. van Cauwenberge PB. Relevant and irrelevant predisposing factors in secretory otitis media. Acta Otolaryngol (Stock). 1984;414:147-53.

18. Zielhuis GA, Rach GH, van Den Broekm P. Predisposing factors for otitis media with effusion in young children. Adv Oto Rhino Laryngol. 1988;40:65-9.

19. Pereira MBR, Ramos BD. Otite média aguda e secretora. J Pediatr (Rio J). 1998;74:21-30.

20. Roberts JE, Burchial MR, Zeisel SA, Neebe EC, Hooper SR, Roush $\mathrm{J}$, et al. Otitis media, the caregiving environment and language and cognitive outcomes at 2 years. Pediatrics. 1998;102:346-54.

21. Giugliani ERJ. Alimentação complementar. J Pediatr (Rio J). 2000;76:253-62.

22. Alho OP, Koivu M, Sorri M, Rantakallio P. Risk factors for recurrent acute otitis media and respiratory infection in infancy. Int J Pediatr Otorhinolaryngol. 1990;19:151-61.

23. White DR, Heavner SB, Hardy SM, Prazma J. Gastroesophageal reflux and Eustachian tube dysfunction in an animal model. Laryngoscope. 2002;112:955-61.

24. Poelmans J, Tack J, Feenstra L. Prospective study on the incidence of chronic ear complaints related to gastroesophageal reflux and on the outcome of antireflux therapy. Ann Otol Rhinol Laryngol. 2002;111:933-8.

25. Caldas Neto S. Otite média secretora. In: Caldas N, Caldas Neto $\mathrm{S}$, Sih T. Otologia e Audiologia Pediátrica. Rio de Janeiro: Revinter; 1999. p. 58-62.

26. Hurst DS, Vengi P, Fredens K. Proof of the association between otitis media with effusion and allergy. In: Lim DJ, Bluestone CD, Casselbrant M, Klein JO, Ogra PL. Recent advances in otitis media. Toronto: Decker; 1996. p. 175-77.

27. Caffarelli C, Savini E, Giordano S, Gianlupi G, Cavagni G. Atopy in children with otitis media with effusion. Clin Exp Allergy. 1998;28:591-6.

28. Sobol SE, Taha R, Schloss MD, Mazer BD, Manoukian JJ, Tewfik $\mathrm{TL}$, et al. TH2 cytokine expression in atopic children with otitis media with effusion. J Allergy Clin Immunol. 2002;110:125-30.

29. Tager IB. Health effects of "passive smoking" in children. Chest. 1989;96:1161-4

30. Kitchins GG. Relationship of environmental tobacco smoke to otitis media in young children. Laryngoscope. 1995;105:1-13.

31. Midgley EJ, Dewey C, Pryce K, Maw R. The frequency of otitis media with effusion in British pre-school children: a guide for treatment. ALSPAC study team. Clin Otolaryngol. 2000;25: 485-91.

32. Bluestone $C D$. Recent advances in the pathogenesis, diagnosis and management of otitis media. Pediatr Clin N Am. 1981;28: 727-55.

Correspondence:

Sandra de Oliveira Saes

Rua Walter Antunes de Freitas, 1-105, Jd. Samambaia

CEP 17018-070 - Bauru, SP

Brazil

Tel.: + 55 (14) $3234.5184 / 3235.7060$

E-mail: ssaes@bol.com.br 